\title{
THE NEW TREASURE OF THE BEGINNING OF THE EARLY IRON AGE FROM THE RIGHT BANK OF THE DON
}

\author{
Roman S. Berestnev \\ Voronezh Regional Museum of Local Lore, Voronezh, Russian Federation
}

\begin{abstract}
The paper is devoted to the publication of new treasure's items of the later pre-Scythian period found in the Podgorensky district of the Voronezh region and transferred for permanent storage to the funds of the Voronezh regional museum of local lore. The treasure consists of 10 bronze items (psalia, bracelet-like rings, horse harness plaques, socketed axe, ring) and 1 iron item (spearhead). These items can also be divided into two groups by the functional criterium - the elements of horse harness and weapons.

The paper studies in detail the chronology of the items and the place of their production. The psalia, slotted plaques of horse harness and bracelet-like rings date from the Novocherkassk's time; the spear dates from the Chernogorovka's time; and the socketed axe dates from the Belozersk's time. Following the conception of S.V. Makhortykh about the dating of the Novocherkassk complex, we make conclusion on the possible coexistence of all objects and date the treasure at the $8^{\text {th }}$ century BC (approx. 714-700 BC). It's been noted that this treasure is time-synchronous to the majority of burials and random finds of the later pre-Scythian period from the territory of the Don region.

Based on the correlation analysis of open antiquities with materials of the known later pre-Scythian complexes, the conclusion has been made about the cultural belonging of the ethnos that left the treasure. Probably, they were Cimmerians of ancient authors. Special attention is paid to the Cimmerian issue in Russian and Ukrainian archaeological studies. We find it possible to preserve the ethnonym 'Cimmerians' for nominating the most ancient nomads of the Northern Black Sea Coast or some of their groups.
\end{abstract}

Key words: treasures, random complex, the Cimmerians, forest-steppe, later pre-Scythian period, Don river.

Citation. Berestnev R.S. The New Treasure of the Beginning of the Early Iron Age from the Right Bank of the Don. Vestnik Volgogradskogo gosudarstvennogo universiteta. Seriya 4, Istoriya. Regionovedenie. Mezhdunarodnye otnosheniya [Science Journal of Volgograd State University. History. Area Studies. International Relations], 2018, vol. 23, no. 4, pp. 15-22. (in Russian). DOI: https://doi.org/10.15688/jvolsu4.2018.4.2

УДК 903.8

Дата поступления статьи: 05.05.2017

ББК 63.442.7(2)-424

Дата принятия статьи: 19.10.2017

\section{НОВЫЙ КЛАД НАЧАЛА РАННЕГО ЖЕЛЕЗНОГО ВЕКА С ТЕРРИТОРИИ ДОНСКОГО ПРАВОБЕРЕЖЬЯ}

\author{
Роман Сергеевич Берестнев \\ Воронежский областной краеведческий музей, г. Воронеж, Российская Федерация
}

\begin{abstract}
Аннотация. Статья посвящена публикации нового клада предметов позднейшего предскифского периода, найденного в Подгоренском районе Воронежской области и переданного на постоянное хранение в $\infty$ фонды Воронежского областного краеведческого музея. В состав клада входят 10 предметов из бронзы (псаخे лии, браслетоподобные кольца, бляхи конской упряжи, кельт, колечко) и 1 - из железа (наконечник копья). По . функциональному назначению предметы также можно разделить на две группы: составляющие конской упряжи и оружие.

В статье подробно рассматривается хронология предметов, устанавливается место их производства. Новочеркасским временем датируются псалии, прорезные бляхи конской упряжи, браслетоподобные кольца; черногоровским временем датируется копье; белозерским временем датируется кельт. Следуя концеп(?) ции С.В. Махортых о датировке новочеркасского комплекса, автор делает вывод о возможном сосуществова-
\end{abstract}


нии всех предметов и датирует клад в рамках VIII в. до н. э. (примерно 714-700 гг. до н. э.). Отмечается, что данный клад синхронен по времени большинству погребений и случайных находок позднейшего предскифского периода с территории Подонья.

На основе корреляционного анализа открытых древностей с материалами известных позднейших предскифских комплексов делается вывод о культурной принадлежности этноса, оставившего клад. Вероятно, это были киммерийцы античных авторов. Особое внимание уделяется киммерийской проблеме в отечественной и украинской археологической науке. Автор считает возможным сохранить этноним «киммерийцы» за древнейшими кочевниками Северного Причерноморья или за какой-то из их частей.

Ключевые слова: клады, случайный комплекс, киммерийцы, лесостепь, позднейший предскифский период, река Дон.

Цитирование. Берестнев Р. С. Новый клад начала раннего железного века с территории Донского правобережья // Вестник Волгоградского государственного университета. Серия 4, История. Регионоведение. Международные отношения. - 2018. - Т. 23, № 4. - C. 15-22. - DOI: https://doi.org/10.15688/jvolsu4.2018.4.2

Введение. В 2016 г. местным жителем Подгоренского района Воронежской области в дар Воронежскому областному краеведческому музею (далее - ВОКМ; шифр музея ВОМ) был передан клад металлических предметов, случайно обнаруженный им в лесу между с. Саприно и с. Семейка в правобережье Среднего Подонья (рис. 1). Со слов дарителя, вещи были найдены под корневищем упавшего дерева; никаких артефактов более им выявлено не было. Клад насчитывает всего 11 предметов (инв. № ВОМ 13030/1-11; А 825-А835). Он оказался достаточно интересным, так как содержит в себе вещи разных культур и хронологических этапов. Настоящая статья призвана не только ввести в научный оборот поступившие в фонды ВОКМ предметы, но и высказать предположения по поводу населения, их оставившего.

Методы, материалы. Итак, в состав клада входят 10 предметов из бронзы (псалии, браслеты, бляхи, кельт, колечко) и 1 - из железа (копье). По функциональному назначению предметы также можно разделить на две группы: составляющие конской упряжи и оружие. Начнем характеристику с наиболее многочисленной группы - принадлежностей узды, которые являются достаточно распространенными находками в предскифских памятниках.

Два псалия, изготовленные из бронзы (рис. 1, 1, 2), относятся к типу «классических» Новочеркасских трехпетельчатых псалиев стержневидной формы с нижним концом в виде изогнутой лопасти и верхним, оканчивающимся круглой плоской шляпкой (тип I по А.А. Иессену, тип Ів по В.Р. Эрлиху, тип 1.1.3.3.1.1 «КлинЯр 1» по С.В. Махортых, тип 2.2.4.І.6 Ново- черкасск по С.Б. Вальчаку). Как один из типов деталей конского снаряжения, трехпетельчатые псалии сложились на Северном Кавказе, пройдя длительный эволюционный путь [4, с. 72; 8, c. $55-58 ; 10$, с. $57 ; 12$, с. $71-72 ; 19$, с. $65 ; 23$, c. $22 ; 24$, c. 153$]$. Данный тип псалиев попал в Северное Причерноморье с территории Кавказа одновременно с киммерийцами [8, с. 57]. Так как аналоги известны и в степи, и в лесостепи, можно предположить, что такие псалии научились изготавливать непосредственно в Северном Причерноморье. Датируются стержневидные трехпетельчатые псалии по аналогиям [17, c. 9-23] в основном в пределах второй половины VIII - начала VII в. до н. э., хотя встречаются и в более ранних комплексах IX в. до н. э.

Следующие предметы из клада - прорезные бронзовые круглые бляхи с крестовидным солярным орнаментом (рис. 1, 4-7). Все они слегка выпуклые и имеют с оборотной стороны петлю для крепления на оголовье. Круг аналогий им в культурах предскифского времени весьма широк в степях Восточной Европы [18, с. 413 , рис. 28,$17 ; 23$, рис. 6 , 9 14 , рис. $8,14,22,31,34-36$, рис. 23,4$]$. Время их наибольшего распространения - новочеркасская ступень.

Еще одна категория предметов из клада, как оказалось также связанная с конской сбруей - браслетоподобные кольца. Они хорошо известны в степях Восточной Европы, имеют аналогии в Преображенском, Ессентуках, Чишхо, Баксане, Герпегеже, Бутенках, Квитках $[1$, рис. 6 ; 3 , табл. $5,7,13 ; 7$, рис. 2 , $14-15 ; 23$, рис. 5,19 , рис. $23,23-24]$. Упомянутые находки встречаются в ареале бытования узды Новочеркасского типа. 


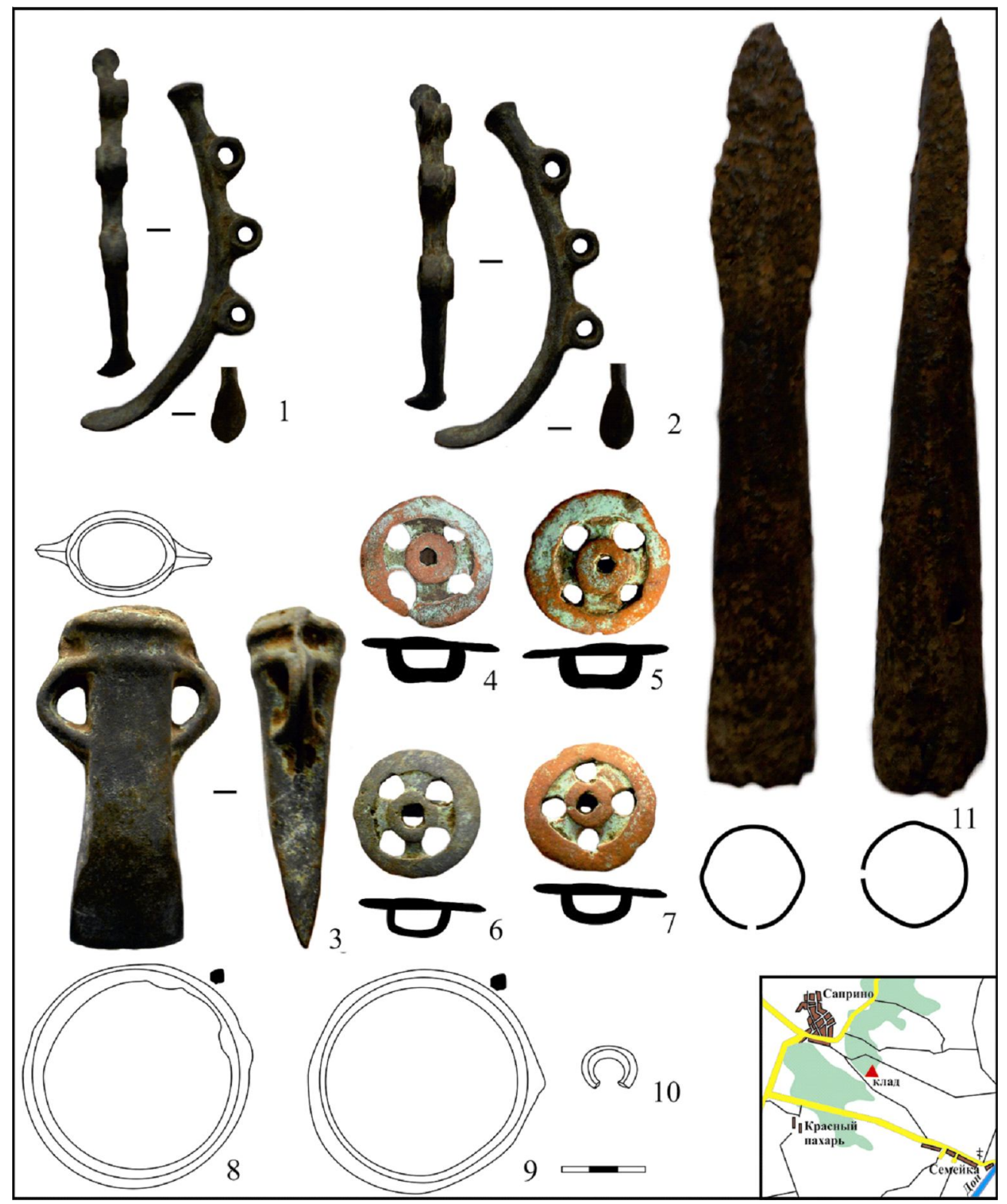

Рис. 1. Клад предметов позднейшего предскифского периода из Донского правобережья:

1, 2 - псалии; 3 - кельт; 4-7 - бляхи; 8, 9 - браслетоподобные кольца; 10 - колечко; 11 - наконечник копья; 1-10 - бронза; 11 - железо

Fig. 1. The treasure of items of the later pre-Scythian period from the right bank of the Don:

1, 2 - psalia; 3 - socketed axe; 4-7 - plaques; 8, 9- bracelet-like rings; 10 - ring; 11 - spearhead; $1-10$ - bronze; 11 - iron

Браслетоподобные кольца, найденные в могилах главным образом лесостепной Украины, долгое время рассматривали как браслеты второй ступени чернолесской культуры [24, с. 70]. Отметим, что подобная трактовка этих изделий являлась дополнительным аргументом в пользу определения комплекса в Бутенках в качестве инвентаря чернолесской могилы $[15$, с. 96]. Однако последующие находки браслетов в весьма отдаленном от чернолесской территории ареале - на Кавказе, среди предметов конской упряжи, позволили вполне справедливо считать их предметами конского снаряжения $[7$, с. 66].

Раскопки кургана Уашхиту в Адыгее в 1988 г. открыли погребения, где узда новочеркасского типа была обнаружена на костях четырех коней in situ. Браслетоподобные кольца располагались здесь на пристяжных лоша- 
дях и были связаны, очевидно, ремнями постромков [25, с. 59-61]. Это открытие впервые археологически зафиксировало использование киммерийцами боевых колесниц. Набором для упряжи четырех лошадей в колесницу ученые считают четыре пары удил, пару колец с подвижными муфтами и пару браслетоподобных колец.

Кроме псалиев и деталей конского головного убора, как указывалось выше, клад предметов содержал литой бронзовый двуушный кельт со втулкой на месте обуха, перпендикулярной лезвию (рис. 1, 3). Его поверхность гладкая. По краю обуха проходит утолщение. Кельт не идентичен, но близок типу «Дремайловка» и датируется по аналогиям с территории Украины [11, с. 173, рис. 23] белозерским этапом позднего бронзового века (в рамках IX в. до н. э.).

Еще одним предметом из клада, связанным с паноплией, является наконечник копья. Он облегченный, с высокой длинной втулкой. Перо лавролистной формы. По перу проходит слабо выраженное осевое утолщение (рис. 1, 11). В последней трети втулки имеются два круглых отверстия, находящихся напротив друг друга. Длина наконечника со втулкой -21 см, без втулки - 9 см, диаметр втулки -3 см.

Подобные наконечники копий, очевидно, не были характерны для паноплии носителей предскифских культур. Самая близкая аналогия анализируемому экземпляру была встречена в старшем протомеотском могильнике у с. Николаевского в Адыгее, соответствующем черногоровским памятникам в киммерийской степи [2, с. 117 , табл. II]. Очевидно, подобные наконечники производились только в Прикубанье, так как аналогий среди кубанских комплексов Центрального Предкавказья выявлено не было. Еще одна черта, характерная для протомеотского производственного центра - параллельные отверстия в последней трети втулки. Они встречены и на железных, и на бронзовых наконечниках копий [24, рис. 84, 18-20, 22]. В целом же для степей Северного Причерноморья находки копий единичны, тогда как преобладают наконечники стрел.

Анализ. В целом данный клад по составляющему его инвентарю (псалии, топо- рик, бляхи, браслетоподобные кольца, наконечники копий) близок предскифским погребениям лесостепной Украины - у с. Бутенки, с. Квитки [23, с. 111 , рис. 5 , с. 112 , рис. 6 , с. 129, рис. 23]. С.А. Скорый датирует подобные комплексы в рамках VIII в. до н. э. (примерно 714-700 гг. до н. э.) [23, с. 61]. С.В. Махортых в общем солидарен с С.А. Скорым, датируя появление колесниц к северу от Главного Кавказского хребта временем после переднеазиатских походов [18, с. 364]. Видимо, и анализируемый комплекс с большой долей вероятности можно соотнести со временем 714-700 гг. до н. э. Хоть основная масса предметов и может быть датирована IX в. (копье, кельт и др.), однако, тот факт, что в состав комплекса входят браслетоподобные кольца - атрибутика колесниц, говорит о VIII веке. Видимо, на территорию Среднего Подонья население, оставившее клад, проникло из степей между Днепром и Предкавказьем - места формирования киммерийской культуры в IX в., о чем свидетельствуют находки, близкие протомеотским, белозерским, новочеркасским комплексам, их разноплановость.

Необходимо заметить, что данный клад не только пополнил коллекцию музея предметами предскифского времени, а до клада их было всего три - пара псалиев (Старая Толучеева, инв. № ВОМ 4617/1, 2) и удила (Ездоцкая, инв. № ВОМ 4616) (рис. 2). Этот комплекс оказался очень важен для истории Подонья в позднейшее предскифское время.

К настоящему моменту на территории Подонья известно всего 18 погребений и случайных находок, относящихся к этому периоду [20, с. 20 , рис. 1]. Анализ их инвентаря позволил А.П. Медведеву поставить вопрос о наличии в лесостепном Подонье двух групп памятников переходного времени [20, с. 20, 21]. Первая группа, по мысли ученого, была оставлена отдаленными потомками местного срубного населения и уже пришлыми племенами. Вторая группа обладает новочеркасскими чертами и датируется VIII-VII вв. до н. э. Как и анализируемый клад, данная группа памятников в Подонье была оставлена уже, видимо, после переднеазиатских походов. Вопрос об оставившем подобные па- 

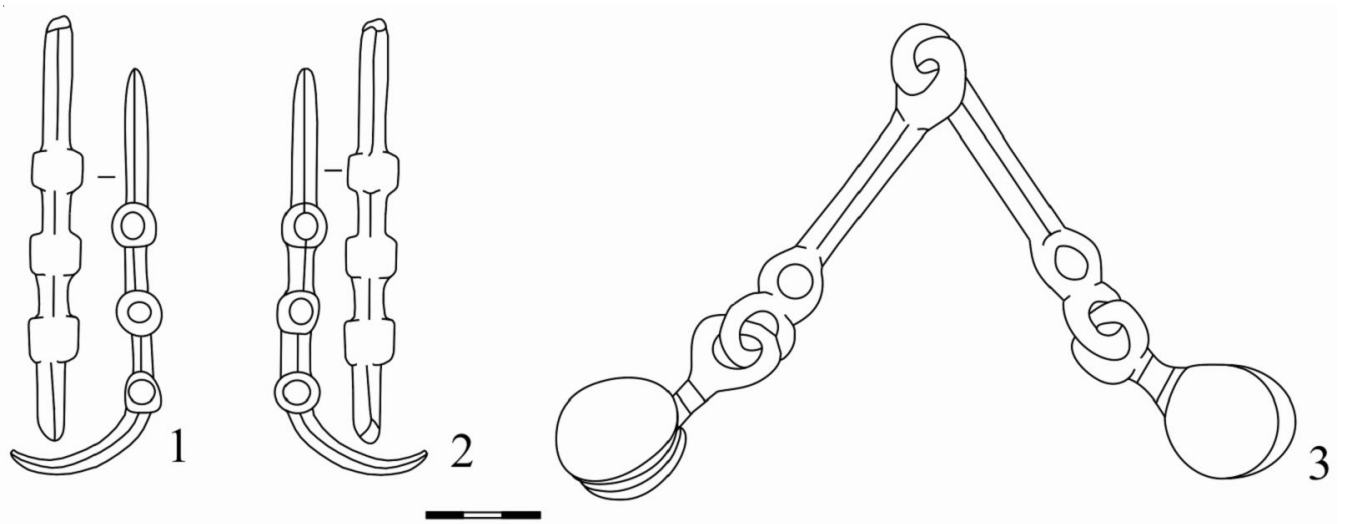

Рис. 2. Предметы позднейшего предскифского периода из коллекции ВОКМ:

1, 2 - псалии (сл. Старая Толучеева бывшего Бобровского уезда Воронежской губернии);

3 - удила (сл. Ездоцкая Коротоякского района Воронежской области); 1-3 - бронза

Fig. 2. The items of the later pre-Scythian period from the collection of the Voronezh Regional Museum of Local Lore:

1, 2 - psalia (the Staraya Tolucheeva settlement, former Bobrovsky district, Voronezh province);

3 - bits (the Ezdotskaya settlement, Korotoyaksky district, Voronezh region); 1-3 - bronze

мятники населении в последнее время является очень дискуссионным.

Закономерным итогом более чем векового изучения киммерийской проблемы стало появление нескольких подходов к ее решению. В трудах ученых 90-х гг. ХХ в. - начала XXI в. наиболее четко отразились как минимум четыре подхода к решению киммерийской проблемы:

- традиционный, представители которого отождествляют памятники новочеркасского типа с киммерийцами Геродота;

- «тереножкинский», согласно которому памятники черногоровского и новочеркасского типов генетически связаны между собой и только с геродотовыми киммерийцами;

- «иессеновский», представители которого считают, что памятники типа «новочеркасского клада» могли принадлежать как киммерийцам, так и скифам;

- современный, отрицающий какую-либо причастность памятников Юга Восточной Европы черногоровско-новочеркасского типа к реальным киммерийцам, археологические следы которых известны только в Восточной Анатолии (Норшун-Тепе, Имирлер).

Первые два подхода свойственны для большинства отечественных и украинских научных школ. Согласно им захоронения новочеркасского типа были оставлены доскифским населением, известным Геродоту под именем киммерийцев $(\mathrm{IV}, 11,12)$. Целостную концепцию принадлежности памятников Северного Причерноморья IX - первой половины VII в. до н. э., в том числе и типа Черногоровки, историческим киммерийцам разработал А.И. Тереножкин [24]. На современном этапе развития киммероведения эту гипотезу с определенными уточнениями активно развивают его ученики - В.В. Отрощенко [21], В.И. Клочко и В.Ю. Мурзин [13], С.В. Махортых [18].

Следующий подход был высказан еще в 50-е гг. XX в. А.А. Иессеном [10]. Согласно этому исследователю памятники типа «новочеркасского клада» могли принадлежать как киммерийцам, так и скифам. Сторонниками этой гипотезы выступали в 70-е гг. ХХ в. А.М. Лесков [16], Б.Н. Граков [5]. В новейшей литературе она нашла наибольшее выражение в книгах Д.С. Раевского и М.Н. Погребовой [22].

Наконец, четвертый подход, отрицающий какую-либо причастность памятников черногоровско-новочеркасского типа к реальным киммерийцам, в последние годы нашел выражение в работах И.В. Куклиной [14], А.И. Иванчика [9] и в коллективной монографии «Киммерийцы» [1].

Выводы. Таким образом, анализируемый клад, очевидно, принадлежал киммерийцам. Скорее всего, он относится к кладам «культовым» или «безвозвратным» (являвшихся ритуальным приношением) по типоло- 
гии И.В. Дубова и В.Н. Седых [6, с. 13]. К сожалению, из-за того, что мы не владеем ситуацией открытия этого комплекса, наш вывод носит гипотетический характер. Но в какой-то степени его ритуальность подтверждают аналогии среди инвентаря в погребальных комплексах лесостепной Украины.

\section{СПИСОК ЛИТЕРАТУРЫ}

1. Алексеев, А. Ю. Киммерийцы: этнокультурная принадлежность / А. Ю. Алексеев, Н. К. Качалова, С. Р. Тохтасьев. - СПб. : Информ.-исслед. ин-т «Ермаков», 1993. - 121 с.

2. Анфимов, Н. В. Протомеотский могильник у с. Николаевского / Н. В. Анфимов // Сборник материалов по археологии Адыгеи. - Майкоп : Адыг. кн. изд-во, 1961. - Т. II. - С. 103-126.

3. Батчаев, В. М. Древности предскифского и скифского периодов / В. М. Батчаев // Археологические исследования на новостройках КабардиноБалкарии в 1972-1979 гг. - Нальчик : Эльбрус, 1985. T. 2. - C. 7-134.

4. Вальчак, С. Б. Конское снаряжение в первой трети I тыс. до н. э. на Юге Восточной Европы / С. Б. Вальчак ; Ин-т археологии РАН. - М. : Таус, 2009. -292 c.

5. Граков, Б. Н. Ранний железный век / Б. Н. Граков. -М. : Изд-во МГУ, 1977. - 235 с.

6. Дубов, И. В. О возможных причинах сокрытия кладов восточных монет в Древней Руси и Скандинавии / И. В. Дубов, В. Н. Седых // Клады: состав, хронология, интерпретация: материалы темат. науч. конф., г. С.-Петербург, 26-29 нояб. 2002 г. - СПб. : Изд-во СПбГУ, 2002. - С. 11-14.

7. Дубовская, О. Р. К интерпретации комплексов типа Новочеркасского клада / О. Р. Дубовская // CA. - 1989. - № 1. - С. 63-69.

8. Дударев, С. Л. Из истории связей населения Кавказа с киммерийско-скифским миром / С. Л. Дударев. - Грозный : Изд-во ЧИГУ, 1991. - 124 с.

9. Иванчик, А. И. Киммерийцы и скифы. Культурно-исторические и хронологические проблемы археологии восточноевропейских степей и Кавказа пред- и раннескифского времени / А. И. Иванчик. М. : Палеограф, 2001.-323 с.

10. Иессен, А. А. К вопросу о памятниках VIIIVII вв. до н. э. на юге Европейской части СССР / А. А. Иессен // СА. - 1953. - Т. XVIII. - С. 49-110.

11. Клочко, В. И. Древний металл Украины / В. И. Клочко, А. В. Козыменко. - Киев : Изд-во ИА НАНУ, 2017. -368 c.

12. Клочко, В. И. О культурно-хронологической интерпретации памятников типа новочеркасского клада / В. И. Клочко, С. В. Махортых // Кимме- рийцы и скифы : тез. докл. - Кировоград : Кировоград. изд-во, 1987. - С. 71-73.

13. Клочко, В. И. О взаимодействии местных и привнесенных элементов скифской культуры / В. И. Клочко, В. Ю. Мурзин // Скифы Северного Причерноморья. - Киев : Наукова думка, 1987. C. $12-19$.

14. Куклина, И. В. Этногеография Скифии по античным источникам / И. В. Куклина. - Л. : Наука, 1985. $-208 \mathrm{c}$.

15. Лесков, А. М. Курганы: находки, проблемы / А. М. Лесков. - Л. : Наука. Ленингр. отд-ние, 1981. $-168 \mathrm{c}$.

16. Лесков, А. М. Предскифский период на Юге Украины : автореф. дис. ... д-ра ист. наук : 07.00.06 / Лесков Александр Михайлович. - М., 1975. - 45 с.

17. Махортих, С. В. Скарби VIII-VII ст. до н. е. на півдні Східної Свропи / С. В. Махортих // Археологія. - 1996. - № 4. - С. 9-24.

18. Махортых, С. В. Культура и история киммерийцев Северного Причерноморья : дис. ... д-ра ист. наук : 07.00.04 / Махортых Сергей Владимирович. - Киев : Изд-во ИА НАНУ, 2008. - 582 с.

19. Махортых, С. В. Скифы на Северном Кавказе / С. В. Махортых. - Киев : Наукова думка, 1991. $136 \mathrm{c}$.

20. Медведев, А. П. Ранний железный век лесостепного Подонья. Археология и этнокультурная история І тыс. до н. э. / А. П. Медведев. - М. : Наука, 1999. - $160 \mathrm{c}$.

21. Отрощенко, В. В. О погребениях черногоровского типа в Нижнем Подонье / В. В. Отрощенко // Историко-археологические исследования в Азове и на Нижнем Дону. - Вып. 13. - Азов : Изд-во Азов. музея-заповедника, 1994. - С. 103-113.

22. Погребова, М. Н. Ранние скифы в свете письменной традиции и археологических данных / М. Н. Погребова, Д. С. Раевский // ВДИ. - 1993. № 4. - С. 110-118.

23. Скорый, С. А. Киммерийцы в украинской Лесостепи / С. А. Скорый. - Киев ; Полтава : Издат. центр «Археология», 1999. - $136 \mathrm{c}$.

24. Тереножкин, А. И. Киммерийцы / А. И. Тереножкин. - Киев : Наукова Думка, 1976. - 224 с.

25. Эрлих, В. Р. Курган Уашхиту и проблема интерпретации некоторых комплексов типа Новочеркасского клада / В. Р. Эрлих // XVI Крупновские чтения по археологии Северного Кавказа : тез. докл. - Ставрополь : Изд-во СГУ, 1990. - С. 59-61.

\section{REFERENCES}

1. Alekseev A.Yu., Kachalova N.K., Tokhtasyev S.R. Kimmeriytsy: etnokulturnaya prinadlezhnost [Cimmerians: Ethnocultural Identity]. 
Saint Petersburg, Information-research institute 'Ermakov' Publ., 1993. 121 p.

2. Anfimov N.V. Protomeotskiy mogilnik u s. Nikolaevskogo [Pre-Meotian Burial Ground near the Nykolaevskoe Village]. Sbornik materialov po arkheologii Adygei [Collected Materials on Archaeology of Adygea]. Maikop, Agygea Publ., 1961, vol. II, pp. 103-126.

3. Batchaev V.M. Drevnosti predskifskogo i skifskogo periodov [Antiquities of the Pre-Scythian and Scythian Periods]. Arkheologicheskie issledovaniya na novostroykakh Kabardino-Balkarii v 1972-1979 gg. [Archaeological Research on New Buildings in Kabardino-Balkaria in 1972-1979]. Nalchik, Elbrus Publ., 1985, vol. 2, pp. 7-134.

4. Valchak S.B. Konskoe snaryazhenie v pervoy treti I tys. do n.e. na yuge Vostochnoy Evropy [Horse Gear in the First Third of the It Millennium BC in the South Eastern Europe]. Moscow, Taus Publ., 2009. 292 p.

5. Grakov B.N. Ranniy zheleznyy vek [The Early Iron Age]. Moscow, MGU Publ., 1977. 235 p.

6. Dubov I.V., Sedykh V.N. O vozmozhnykh prichinakh sokrytiya kladov vostochnykh monet $\mathrm{v}$ Drevney Rusi i Skandinavii [On Possible Reasons for Hiding the Treasures of Eastern Coins in Ancient Russia and Scandinavia]. Klady: sostav, khronologiya, interpretatsiya: materialy temat. nauch. konf. [Treasures: Composition, Chronology, Interpretation: Materials of the Thematic Scientific Conference]. Saint Petersburg, Izd-vo SPbGU, 2002, pp. 11-14.

7. Dubovskaya O.R. K interpretatsii kompleksov tipa Novocherkasskogo klada [On the Interpretation of the Novocherkassk Treasure-Like Complexes]. Sovetskaya arkheologiya [Soviet Archaeology], 1989, no. 1, pp. 63-69.

8. Dudarev S.L. Iz istorii svyazey naseleniya Kavkaza s kimmeriysko-skifskim mirom [From the History of Relations between the Population of the Caucasus and the Cimmerian-Scythian World]. Grozny, Izd-vo ChIGU, 1991. $124 \mathrm{p}$.

9. Ivanchik A.I. Kimmeriytsy i skify. Kulturnoistoricheskie $i$ khronologicheskie problemy arkheologii vostochnoevropeyskih stepey $i$ Kavkaza pred- $i$ ranneskifskogo vremeni [Cimmerians and Scythians. Cultural-Historical and Chronological Problems of the Archaeology of the Eastern European Steppes and Caucasus of Pre- and Early Scythian Times]. Moscow, Paleograf Publ., 2001. 323 p.

10. Iessen A.A. K voprosu o pamyatnikakh VIIIVII vv. do n. e. na yuge Evropeyskoy chasti SSSR [On the Monuments of the $8^{\text {th }}-7^{\text {th }} \mathrm{cc}$. BC in the South of the European Part of the USSR]. Sovetskaya arkheologiya [Soviet Archaeology], 1953, vol. XVIII, pp. 49-110.

11. Klochko V.I., Kozymenko A.V. Drevniy metall Ukrainy [Ancient Metal of Ukraine]. Kiev, IA NANU Publ., 2017. 368 p.
12. Klochko V.I., Makhortykh S.V. O kulturnokhronologicheskoy interpretatsii pamyatnikov tipa novocherkasskogo klada [On the Cultural and Chronological Interpretation of the Novocherkassk Treasure-Like Monuments]. Kimmeriytsy i skify: tez. dokl. [Cimmerians and Scythians: Reports' Theses]. Kirovograd, Kirovograd Publ., 1987, pp. 71-73.

13. Klochko V.I., Murzin V.Yu. O vzaimodeystvii mestnykh i privnesennykh elementov skifskoy kultury [On the Interaction of Local and Introduced Elements of Scythian Culture]. Skify Severnogo Prichernomorya [Scythians of the Northern Black Sea Region]. Kiev, Naukova dumka Publ., 1987, pp. 12-19.

14. Kuklina I.V. Etnogeografiya Skifii po antichnym istochnikam [Ethnogeography of Scythia According to Ancient Sources]. Leningrad, Nauka Publ., 1985. 208 p.

15. Leskov A.M. Kurgany: nakhodki, problemy [Barrows: Finds, Problems]. Leningrad, Nauka Publ., 1981. $168 \mathrm{p}$.

16. Leskov A.M. Predskifskiy period na Yuge Ukrainy: avtoref. dis. ... d-ra ist. nauk [Pre-Scythian Period in the South of Ukraine. Dr. hist. sci. abs. diss.]. Moscow, 1975. 45 p.

17. Makhortykh S.V. The Treasures of the $8^{\text {th }}-$ $7^{\text {th }} \mathrm{cc}$. BC in the South Eastern Europe. Arkheologiya [Archaeology], 1996, no. 4, pp. 9-24. (in Ukrainian).

18. Makhortykh S.V. Kultura i istoriya kimmeriytsev Severnogo Prichernomorya: dis. ... $d$-ra ist. nauk [Culture and History of the Cimmerians of the Northern Black Sea Region. Dr. hist. sci. diss.]. Kiev, 2008. 582 p.

19. Makhortykh S.V. Skify na Severnom Kavkaze [Scythians in the North Caucasus]. Kiev, Naukova Dumka Publ., 1991. 136 p.

20. Medvedev A.P. Ranniy zheleznyy vek lesostepnogo Podonya. Arkheologiya i etnokulturnaya istoriya I tys. do n. e. [The Early Iron Age of the ForestSteppe Basin of the Don River. Archaeology and Ethnocultural History of the $\mathrm{I}^{\text {st }}$ Millennium BC]. Moscow, Nauka Publ., 1999. 160p.

21. Otroshchenko V.V. O pogrebeniyakh chernogorovskogo tipa v Nizhnem Podonye [About Burials of the Montenegrin Type in the Lower Don]. Istoriko-arkheologicheskie issledovaniya $v$ Azove $i$ na Nizhnem Donu [Historical and Archaeological Research in Azov and the Lower Don]. Azov, Azov Museum Reserve Publ., 1994, iss. 13, pp. 103-113.

22. Pogrebova M.N., Raevskiy D.S. Rannie skify $\mathrm{V}$ svete pismennoy traditsii $\mathrm{i}$ arkheologicheskikh dannykh [Early Scythians in the Light of Writing Tradition and Archaeological Data]. Vestnik drevney istorii [The Bulletin of Ancient History], 1993, no. 4, pp. 110-118.

23. Skoryy S.A. Kimmeriytsy v ukrainskoy Lesostepi [The Cimmerians in the Ukrainian Forest- 


\section{АРХЕОЛОГИЯ}

Steppe]. Kiev; Poltava, Arkheologiya Publ., 1999. $136 \mathrm{p}$.

24. Terenozhkin A.I. Kimmeriytsy [The Cimmerians]. Kiev, Naukova Dumka Publ., 1976.224 p.

25. Erlikh V.R. Kurgan Uashkhitu i problema interpretatsii nekotorykh kompleksov tipa
Novocherkasskogo klada [The Mound of Uuschit and the Problem of Interpretation of Some Novocherkassk Treasure Complexes]. XVI Krupnovskie chteniya po arkheologii Severnogo Kavkaza: tez. dokl. [16th Reading on the archaeology of the North Caucasus in the Memory of E.I. Krupnov]. Stavropol, Izd-vo SGU, 1990, pp. 59-61.

\section{Information about the Author}

Roman S. Berestnev, Candidate of Sciences (History), Senior Researcher, Curator of the archeological collection, Voronezh Regional Museum of Local Lore, Plekhanovskaya St., 29, 394018 Voronezh, Russian Federation, roman.berestnev2016@yandex.ru, https://orcid.org/0000-0003-0406-0089

\section{Информация об авторе}

Роман Сергеевич Берестнев, кандидат исторических наук, старший научный сотрудник, хранитель коллекции «Археология», Воронежский областной краеведческий музей, ул. Плехановская, 29, 394018 г. Воронеж, Российская Федерация, roman.berestnev2016@yandex.ru, https://orcid.org/ 0000-0003-0406-0089 